\title{
International children's accelerometry database (ICAD): Design and methods
}

Lauren B Sherar ${ }^{1 *}$, Pippa Griew², Dale W Esliger ${ }^{1}$, Ashley R Cooper ${ }^{3}$, Ulf Ekelund ${ }^{4,5}$, Ken Judge ${ }^{6}$ and Chris Riddoch ${ }^{6}$

\begin{abstract}
Background: Over the past decade, accelerometers have increased in popularity as an objective measure of physical activity in free-living individuals. Evidence suggests that objective measures, rather than subjective tools such as questionnaires, are more likely to detect associations between physical activity and health in children. To date, a number of studies of children and adolescents across diverse cultures around the globe have collected accelerometer measures of physical activity accompanied by a broad range of predictor variables and associated health outcomes. The International Children's Accelerometry Database (ICAD) project pooled and reduced raw accelerometer data using standardized methods to create comparable outcome variables across studies. Such data pooling has the potential to improve our knowledge regarding the strength of relationships between physical activity and health. This manuscript describes the contributing studies, outlines the standardized methods used to process the accelerometer data and provides the initial questions which will be addressed using this novel data repository.
\end{abstract}

Methods: Between September 2008 and May 2010 46,131 raw Actigraph data files and accompanying anthropometric, demographic and health data collected on children (aged 3-18 years) were obtained from 20 studies worldwide and data was reduced using standardized analytical methods.

Results: When using $\geq 8, \geq 10$ and $\geq 12$ hrs of wear per day as a criterion, $96 \%, 93.5 \%$ and $86.2 \%$ of the males, respectively, and $96.3 \%, 93.7 \%$ and $86 \%$ of the females, respectively, had at least one valid day of data.

Conclusions: Pooling raw accelerometer data and accompanying phenotypic data from a number of studies has the potential to: a) increase statistical power due to a large sample size, b) create a more heterogeneous and potentially more representative sample, c) standardize and optimize the analytical methods used in the generation of outcome variables, and d) provide a means to study the causes of inter-study variability in physical activity. Methodological challenges include inflated variability in accelerometry measurements and the wide variation in tools and methods used to collect non-accelerometer data.

\section{Background}

In adults, physical activity is strongly and inversely associated with risk of most major chronic diseases, including obesity, type 2 diabetes, breast and bowel cancer, cardiovascular disease (CVD), musculoskeletal health and psychological well-being [1]. Disease endpoints associated with lack of physical activity are rarely seen in children and it is only in recent years that a consistent association between physical activity and a range of health parameters in children has been described [2]. Understanding the strength of the associations between

\footnotetext{
* Correspondence: lauren.sherar@usask.ca

${ }^{1}$ College of Kinesiology, University of Saskatchewan, Saskatoon, SK, Canada Full list of author information is available at the end of the article
}

physical activity and health outcomes has been restricted by difficulties in accurately quantifying physical activity; a complex, multi-dimensional and highly variable behavior. Self-report methods can capture a few sustained activities (e.g. physical education lessons, team sports, etc.) that may be memorable, but children find it difficult to quantify the duration, frequency or intensity of the activity, especially as most children's activity does not occur in sustained bouts - rather, it occurs in numerous short spontaneous bursts of varying intensities [3-5] which are difficult to recall. The quantification of this large volume of 'lifestyle' activity is improved with the use of objective methods. Accelerometers have substantially enhanced our ability to obtain precise

\section{Biomed Central}


measurements of the volume, pattern, frequency, intensity and duration of children's physical activity and sedentary behaviours.

As studies have increasingly adopted objective measurement technologies (e.g., accelerometers) to assess children's physical activity, stronger associations with health outcomes have been identified [6-16]. For example, results from a cross sectional sample $(\mathrm{N}=2,049)$ of British 9-10 yr olds showed a strong inverse graded association between objectively measured physical activity and adiposity and markers of cardiometabolic risk [6]. These findings were consistent across ethnic groups (South Asian, African Caribbean and White European) and mirror results previously found in European children [14]. Results from the Avon Longitudinal Study of Parents and Children (ALSPAC) suggest similar strong relationships between physical activity (also measured by accelerometry) and obesity [13,15] and bone health [16]. Incorporation of accelerometry into large scale surveys has yielded new nationally representative findings. For example, inverse dose-response relations were observed between total physical activity and moderate-to-vigorous physical activity (MVPA) and blood pressure [9] and between medium-to-long bouts of MVPA and BMI [8] in youth (8-17 yrs) from the United States' National Health and Nutrition Examination Survey. Lastly, new insights into the predictors of activity in children have also been identified [17-22]. These findings demonstrate that when large sample size is combined with accurate measurement of outcome and predictor variables, important new insights into the physical activity behaviors of children are obtained.

To date, accelerometer data has been collected in different countries, across diverse cultures, from age ranges encompassing the full childhood and adolescent period, and including a broad range of predictor variables and associated health outcomes. However, because of the multitude of methods used to analyze raw accelerometer files, outcome variables (such as minutes spent in MVPA) are not comparable across studies. Collecting, pooling and reducing raw accelerometer data using standardized methods would create comparable outcome variables across studies. Such data pooling has the potential to improve our knowledge regarding the strength of relationships between physical activity and health outcomes through an increase in statistical power provided by a much larger sample size. Data pooling across studies can also lead to a more heterogeneous (e. g. in terms of ethnicity, culture, socio-economic status, etc.) and thus potentially representative sample. Finally, the study of the causes of variability in physical activity across related contributing studies may also lead to novel insights into socio-cultural and physical environment influences on physical activity.
The aim of this paper is to describe the design and protocols of the International Children's Accelerometry Database (ICAD) project, and how the pooled dataset can be used to address the following main research questions:

1. What are the physical activity levels and patterns of children from diverse geographical backgrounds and how do these vary by age, gender and BMI?

2. What are the dose-response associations between sedentary behaviour, sub-components of physical activity and metabolic health outcomes?

3. To what extent are levels of physical activity in children, and/or the dose response relationship between activity and health outcomes, patterned by measures of socio-economic position in such a way as to provide prima facie evidence of health inequalities?

\section{Methods}

Between September, 2008 and May, 2010, 46,131 raw Actigraph data files and accompanying anthropometric, demographic and health data (where available) collected on children (3-18 yrs, specifically 2.5-18.4 yrs) were obtained from 20 studies worldwide and re-analyzed using standard techniques.

\section{Recruitment of studies}

In the fall of 2008, a pragmatic search for potential contributors was undertaken. Datasets were identified through personal contacts (5 studies) and Pubmed searchs (19 studies; using the search-string "accelerometer", "children", "physical activity"). From the search studies which used a version of the Actigraph accelerometer (Actigraph LLC, Pensacola, FL) in children 3-18 years and with sample size $>400$ were identified. When a potentially eligible study was identified the Principle Investigator of the study was emailed to gauge general interest regarding pooling of their data. The data sharing policies were communicated at this point.

After a principle investigator or research group had consented for their data to be pooled, contact was made with their data manager to transfer data. Data was transferred using a secured FTP drop-site. Raw accelerometer. DAT files and additional phenotypic information (usually in SPSS, excel or SAS format) were deposited. Contextual information on the methods of data collection and variable coding was also garnered through telephone administered questionnaires.

World-wide, 24 studies were approached and invited to contribute data. The eligibility criteria for inclusion were: 1) physical activity data in the form of raw accelerometer (.dat) files from a version of a waist worn Actigraph accelerometer (e.g. 7164, 71256, GT1M ${ }^{1}$ ) on children 3-18 years, (2) accompanying data, at a minimum, of gender, age and measured height and weight. 
Three of the invited groups chose not to contribute data. One further study could not be included because the data did not meet the minimum inclusion criteria. Hence, 20 of the 24 invited studies contributed data. Formal data sharing agreements and policies were established between ICAD and all partners. Each partner consulted with their research ethics board to confirm sufficient ethical approval had been attained for contributing the data. All individual data within the pooled data set were allocated a unique and non-identifiable participant ID to ensure anonymity of data.

\section{The Actigraph accelerometer}

The Actigraph family of accelerometers have become the de facto standard for measuring physical activity, having been used in the studies large and small the world over. These Actigraph models are uniaxial ${ }^{2}$ accelerometers that detect vertical accelerations in the magnitude of 0.05-2.13 $\mathrm{g}$ with a frequency response of 0.25$2.50 \mathrm{~Hz}$ [23]. These Actigraph accelerometers are small (e.g. GT1M model is $4.5 \times 3.5 \times 1.0 \mathrm{~cm}$ and $43 \mathrm{~g}$ ) and in each of the contributing studies were worn on a belt fastened around the waist. When the Actigraph is accelerated, a voltage signal is generated proportional to the intensity of the acceleration. The acceleration signal is sampled at $10 \mathrm{~Hz}$ (7164 and 71256 model) or $30 \mathrm{~Hz}$ (GT1M model) and summarized in user-defined intervals (epochs) according to the users specific needs. Once downloaded, these temporally stamped data can be analyzed to provide measures of activity level (volume), and intensity, as well as daily, weekly and seasonal activity patterns [24]. These Actigraph models have demonstrated acceptable levels of technical reliability [25-28]. In addition the Actigraph has been shown to be valid in both children and adolescents [29]. Ekelund et al. [30] assessed the validity of the Actigraph in freeliving children using energy expenditure measured by doubly labeled water (DLW) as the criterion measure. Accelerometer output (counts/min) was related to physical activity level $(\mathrm{r}=0.58, \mathrm{P}<0.01)$. This can be compared with correlations of self report versus gold standard measurements that are usually in the range of $\mathrm{r}=0.0-0.2[30]$.

\section{Characteristics of the contributing studies}

The characteristics of the contributing studies are outlined in Table 1. The majority of the studies are located in Europe $(\mathrm{N}=13)$. The other studies are located in the United States $(\mathrm{N}=4)$, Brazil $(\mathrm{N}=1)$ and Australia $(\mathrm{N}=$ 2). Study designs include cross-sectional, longitudinal, closed cohort, and intervention studies. The information provided in Table 1 refers to the data actually deposited in ICAD. For example, in the 1993 Pelotas Birth Cohort Study [31-33] accelerometry was only conducted at one wave (at 13 years) of the longitudinal study and thus, within ICAD, this study is described as cross-sectional. In total, 44,454 viable baseline and repeated measured files were contributed from a total of 31,976 participants (including 12,022 boys and 19,954 girls) aged 2.5-18.4 yrs. With the exception of the female only sample, Project TAAG, the contributing studies collected data on both males and females.

Data were analyzed using KineSoft version 3.3.20 (KineSoft, Saskatchewan, Canada; http://www.kinesoft. org).

\section{Accelerometer Data Cleaning}

Partners were requested to contribute all raw Actigraph data files (i.e. files with a. dat file extension). All studies were able to meet this request with the exception of the NHANES studies (see below for discussion of the special treatment for this study). In total 46,131 files were deposited (Figure 1). Of these, 298 (0.6\%) duplicate files for the same participant were removed. This occurred when two monitors were placed on an individual, either as a part of a validation study or to increase the chances of obtaining a reliable file (i.e. if one monitor fails, there will be data from another monitor). In these instances the files were viewed and if one was corrupt, the noncorrupt file was used. If both files were 'not corrupt' then the first labeled file was used. A total of 419 (0.9\%) files were not included because they did not have the minimum accompanying variables. Finally, 219 (0.5\%) files deemed to have no wear time data (discussed in detail below) and $5(0.01 \%)$ corrupt files were unable to be processed and were not included in the database. This resulted in the processing of 45,190 accelerometer files.

The files in the database were 'flagged' if they had one of more of the following characteristics (see Figure 2 for an example of an 'OK' file and Figures 3, 4 and 5 for examples of files flagged as spurious):

1. Overnight wear of $\geq 10$ minutes at hrs 2,3 and/or 4 am. Visual graphing of these files was used to determine the reason for the overnight wear. The four reasons for overnight wear were: i) Legitimate wearing of the monitor overnight, ii) 'Temporally shifted' file (Figure 3), iii) Potentially spurious device that does not return to baseline (zero) (Figure 4), iv) Malfunctioned unit (Figure 5). A 'temporally shifted' file is when the time stamping of the data is shifted by a number of hours which results in greater than expected consecutive zeros during the day and activity counts during the night on each day of monitoring.

2. Plateau (3 consecutive counts at the same number) at a count $\geq 10$. This was a good indicator of technical faults with the device (with plateaus occurring most often at 32767 counts) (Figure 5). 
Table 1 Details of the 20 studies that contributed data to the International Children's Accelerometry Database (ICAD)

\begin{tabular}{|c|c|c|c|c|c|c|c|c|c|c|c|c|}
\hline Study Name* & & Yrs & $\underset{* *}{\text { Months }}$ & Country & Study design & $\begin{array}{c}\mathrm{N} \\
\text { Waves }\end{array}$ & $\begin{array}{c}\mathrm{N} \\
\text { Subjects }\end{array}$ & $\begin{array}{c}\mathrm{N} \\
\text { Files }\end{array}$ & $\begin{array}{l}\text { Age } \\
\text { (y) }\end{array}$ & Model & Epoch & Days*** \\
\hline ALSPAC & [56] & $03-07$ & All & England & Long. & 2 & 6060 & 10811 & $10-15$ & $\begin{array}{c}7164 \\
71256, \\
\text { GT1M }\end{array}$ & 60 & 7 \\
\hline Ballabeina Study & {$[57]$} & 08-09 & June-Sept & Switzerland & Inter. & 2 & 403 & 988 & $4-8$ & GT1M & 15 & 5 \\
\hline $\begin{array}{l}\text { Belgium Pre-School } \\
\text { Study }\end{array}$ & {$[58-60]$} & $\begin{array}{c}06 ; 08- \\
09\end{array}$ & $\begin{array}{l}\text { Oct- } \\
\text { March }\end{array}$ & Belgium & Cross. & 1 & 433 & 433 & $3-7$ & GT1M & 15 & $2-4$ \\
\hline CHAMPS (UK) & {$[61,62]$} & $06-07$ & Nov-May & England & Cross. & 1 & 562 & 562 & $3-17$ & GT1M & 60 & 7 \\
\hline CHAMPS (US) & {$[63]$} & $03-06$ & All & $\begin{array}{l}\text { United } \\
\text { States }\end{array}$ & Cross. & 1 & 469 & 469 & $3-6$ & 7164 & 10 & 4 \\
\hline$\overline{C L A N^{a}}$ & {$[21,64,65]$} & $\begin{array}{l}01 ; 04 ; \\
06\end{array}$ & $\begin{array}{l}\text { March- } \\
\text { Dec }\end{array}$ & Australia & Long. & 3 & 1126 & 2065 & $5-18$ & $\begin{array}{l}\text { 7164, } \\
\text { GT1M }\end{array}$ & 60,20 & 6 \\
\hline $\mathrm{CSClS}$ & {$[66,67]$} & 01-05 & Oct-May & Denmark & Inter. & 2 & 615 & 1150 & $6-11$ & 7164 & 60 & 4 \\
\hline EYHS (Denmark) & {$[68,69]$} & $\begin{array}{l}\text { 97-98; } \\
03-04\end{array}$ & All & Denmark & Closed Cohort & 2 & 1308 & 1739 & $8-18$ & 7164 & 60 & 4 \\
\hline EYHS (Estonia) & [69] & 98-99 & Aug-May & Estonia & Cross. & 1 & 662 & 662 & $8-17$ & 7164 & 60 & 4 \\
\hline HEAPS & {$[70,71]$} & $\begin{array}{c}02-03 ; \\
06\end{array}$ & Feb-Dec & Australia & Long. & 2 & 1362 & 1714 & $4-16$ & $\begin{array}{l}\text { 7164, } \\
\text { GT1M }\end{array}$ & 60 & 7 \\
\hline $\begin{array}{l}\text { lowa Bone } \\
\text { Development Study }\end{array}$ & {$[72,73]$} & $98-07$ & Sept-Dec & $\begin{array}{l}\text { United } \\
\text { States }\end{array}$ & Long. & 4 & 437 & 1996 & $5-15$ & 7164 & 60 & $4-5$ \\
\hline KISS & [74] & $05-06$ & May-Nov & Switzerland & Inter. & 2 & 433 & 909 & $6-14$ & $\begin{array}{l}\text { 7164, } \\
\text { GT1M }\end{array}$ & 60 & 7 \\
\hline MAGIC & {$[75]$} & 02 & Sept-Oct & Scotland & Cross. & 1 & 462 & 462 & $4-5$ & 7164 & 60 & 6 \\
\hline NHANES & {$[8,9,76,77]$} & $\begin{array}{l}03-04 ; \\
05-06\end{array}$ & All & $\begin{array}{l}\text { United } \\
\text { States }\end{array}$ & Cross. & 2 & 5174 & 4970 & $6-18$ & GT1M & 60 & 7 \\
\hline EYHS (Norway) & {$[69,78]$} & $99-00$ & $\begin{array}{l}\text { Feb-June; } \\
\text { Oct }\end{array}$ & Norway & Cross. & 1 & 391 & 391 & $9-10$ & 7164 & 60 & 4 \\
\hline PEACH & [79] & 06-09 & Sept-July & England & Long. & 2 & 1232 & 2091 & $10-13$ & GT1M & 15 & 7 \\
\hline $\begin{array}{l}\text { Pelotas } 1993 \text { Birth } \\
\text { Cohort }\end{array}$ & {$[31-33]$} & $06-07$ & Aug-Feb & Brazil & Cross. & 1 & 457 & 457 & $13-14$ & GT1M & 5 & 4 \\
\hline Portugal EYHS & {$[69,80]$} & $99-00$ & Jan-July & Portugal & Long. & 2 & 1242 & 1386 & 8-18 & GT1M & 60 & 4 \\
\hline Project TAAG & {$[81,82]$} & $02-06$ & Oct-May & $\begin{array}{l}\text { United } \\
\text { States }\end{array}$ & $\begin{array}{c}\text { Closed Cohort } \\
\text { Inter. }\end{array}$ & 2 & 7148 & 8995 & $10-17$ & 7164 & 30 & 7 \\
\hline \multirow[t]{2}{*}{ SPEEDY } & {$[7,6,83]$} & 07 & Feb-July & England & Cross. & 1 & 2000 & 2000 & $9-11$ & GT1M & 5 & 7 \\
\hline & & & & & & Total & 31976 & 44544 & & & & \\
\hline
\end{tabular}

Note: *See Additional file 1, Table S8 for full name of study; ** Approximate months during which data collection (across all waves) occurred; *** Days = Number of days of Actigraph deployment. N Files = the total number of files contributed from each study that are present in the database (excluding spurious and 'temporally shifted' files); Long - Longitudinal; Cross = Cross-sectional; Inter. = Intervention. Note: the number of participants will differ from the number of files when a study has repeated measures on the same individual (e.g. longitudinal and or closed cohort design); ${ }^{a}$ Baseline wave of CLAN was named CLASS ("Children's Leisure Activities Study") in early publications.

A variable was included in the database which indicates files considered spurious $(556(1.2 \%))$ and 'temporally shifted' $(180(0.4 \%))$. It is recommended that these files are excluded from further analysis. Thus the final database includes data obtained from 44,454 'viable' accelerometer files (Figure 1).

\section{Non-accelerometer data}

To accompany the accelerometer files, all projects contributed additional participant information. Studies were included in ICAD if they had a minimum of age, gender, height and weight. However, within a study, individuals were included if they had age and gender at a minimum (i.e. could be missing height and weight). Where available, additional information including body composition (e.g. circumference measures, skinfolds), health markers (e.g. blood pressure, cholesterol), economic indicators (e. g. household income), parental information (e.g. height, weight) and behavioral variables (e.g. school travel mode, TV viewing) were also requested.

For a variable to be included in the database, it had to be present in at least 3 contributing studies. The coding procedure for all variables was standardized across projects to ensure uniformity within the database. Where necessary, the appropriate formulae were used to re-calculate the unit of measurement for body composition 


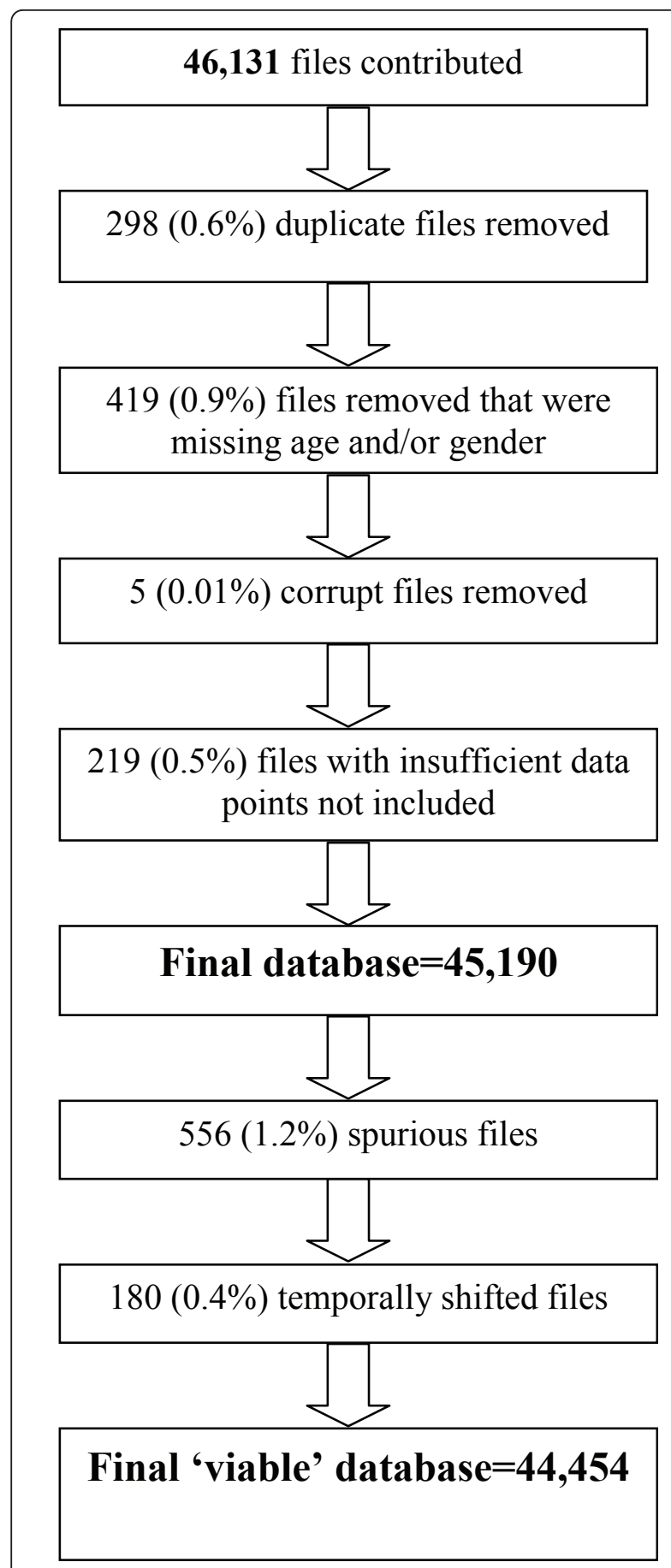

Figure 1 The final sample size of the pooled database.

variables. To create standardized categorical variables the response categories used by different projects were compared and, where appropriate, combined category options were created for ICAD. Original participant responses were then re-coded to the new ICAD categories. See Additional file 1 for a full description of all non-accelerometer variables and further re-coding details.
Final sample characteristics

Figure 6 shows the sample size at each chronological age for girls and boys. The numbers include all the viable data (i.e. excluding spurious and temporally shifted files) in the final database (total $=44,454)$. Figure 6a shows the age distribution of all files, including repeated measures on the same individual. Figure $6 \mathrm{~b}$ shows the distribution of the baseline measures $(\mathrm{N}=$ $31,976)$ only (thus participants are only featured once). At most ages there is a fairly equal representation of girls and boys with the exception of age 13 and 14, where more females are represented. This is primarily due to the contribution of data at these ages from Project TAAG, a female-only study.

\section{Data Collection Information}

The 20 contributing studies collected accelerometer data using three versions of the Actigraph family of monitors (see Table 1). Of the 20 studies, the Actigraph (7164, also known as the CSA and MTI) was used in 8, the newer Actigraph GT1M, model was used in 8, and 4 studies used a mixture of both models including one where the 71256 model was used (which only differs from the 7164 with respect to the size of the memory).

The fact that epoch length influences the interpretation of accelerometer data has been well documented [34-40]. An epoch, refers to the amount of time over which activity counts are summed and stored. Epochs varied from 5 seconds to 60 seconds (see Table 1). The older studies tended to collect at 60 second epochs, because the older generation accelerometers were only capable of storing data collected using epoch lengths of $<60$ seconds for a limited number of days. Newer generations of the Actigraph have increased storage capacity allowing for higher resolution data to be collected while still being able to measure physical activity for at least 7 days. For the purpose of the pooled dataset it was necessary that all outcome variables be comparable; therefore, all files which used an epoch $<60$ seconds were reintegrated up to 60 seconds for analysis using an automated tool in the KineSoft toolbox.

\section{Data reduction}

\section{Determination of accelerometer wear and non-wear}

The decision was taken to consider accelerometers as not worn if a period of 60 minutes of consecutive zeros, allowing for 2 minutes of non-zero interruptions, was encountered anywhere in the data array. All other count data contributed to the determination of accelerometer wear time. Non-wear data received special coding in order to separate and exclude the non-wear zeros from the legitimate zeros that often occur during periods of sedentary behavior. No imputation or data modeling was used to replace missing data. 


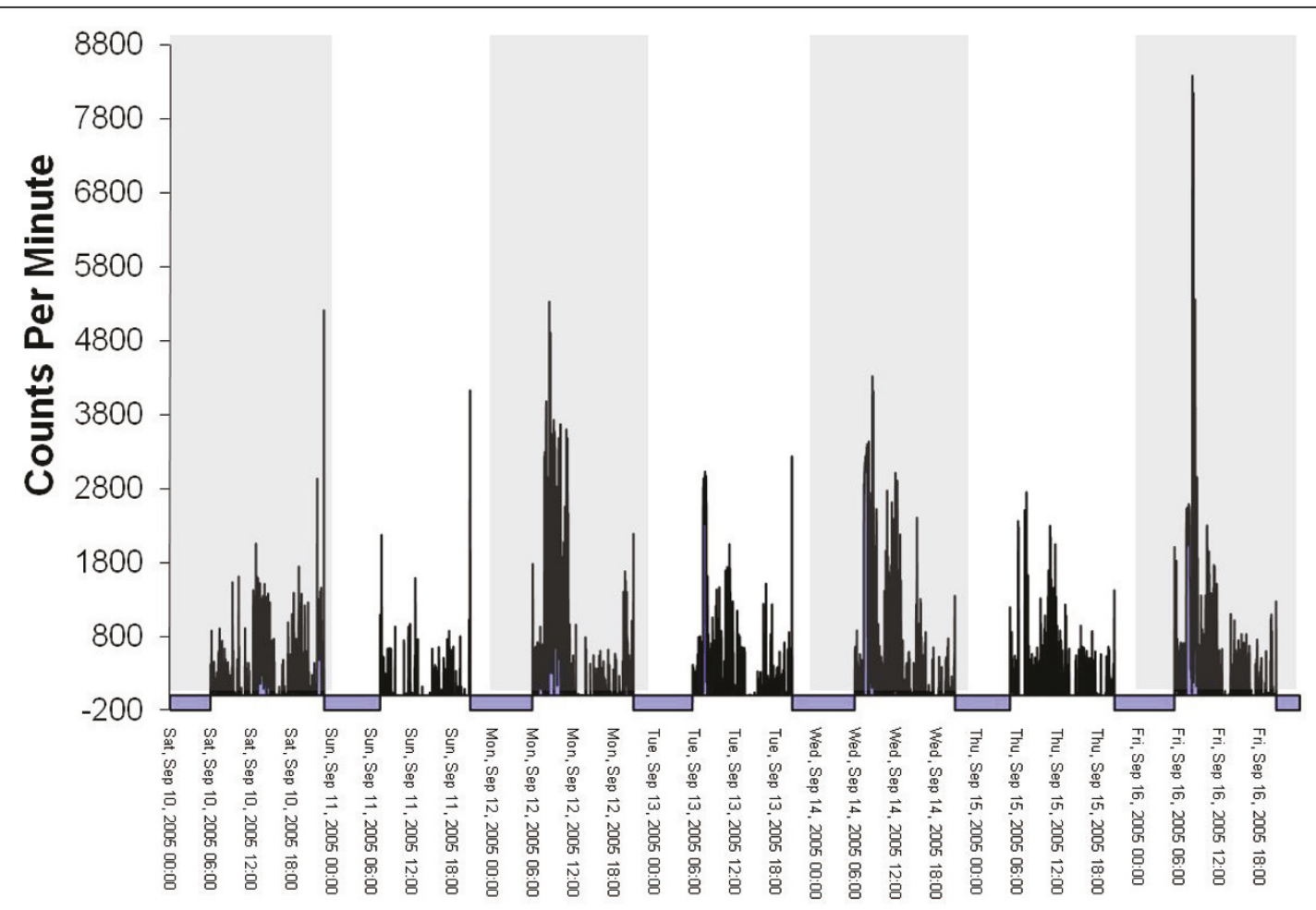

Figure 2 Graphical example of an 'OK' file.

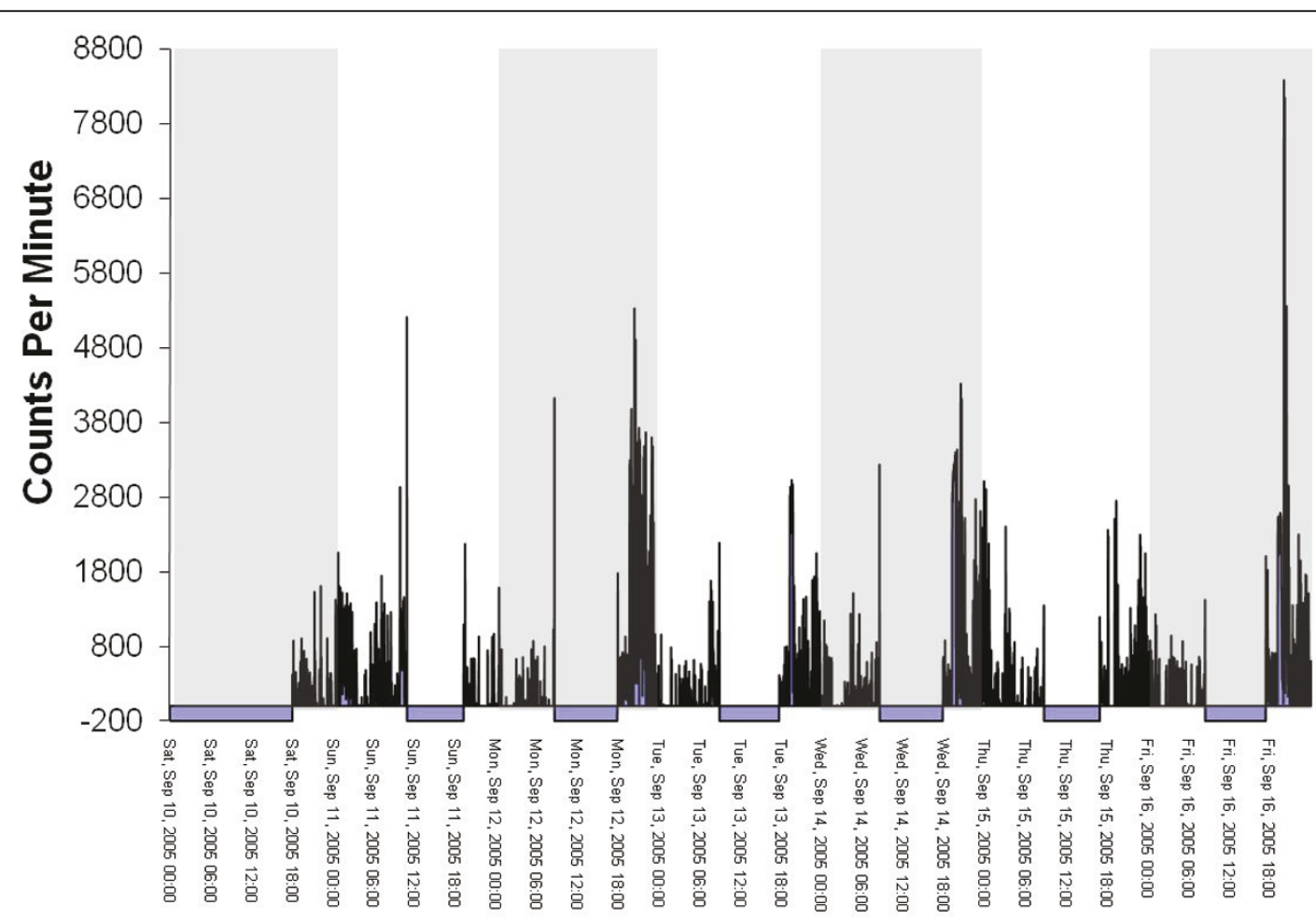

Figure 3 Graphical example of a 'temporally shifted' file 


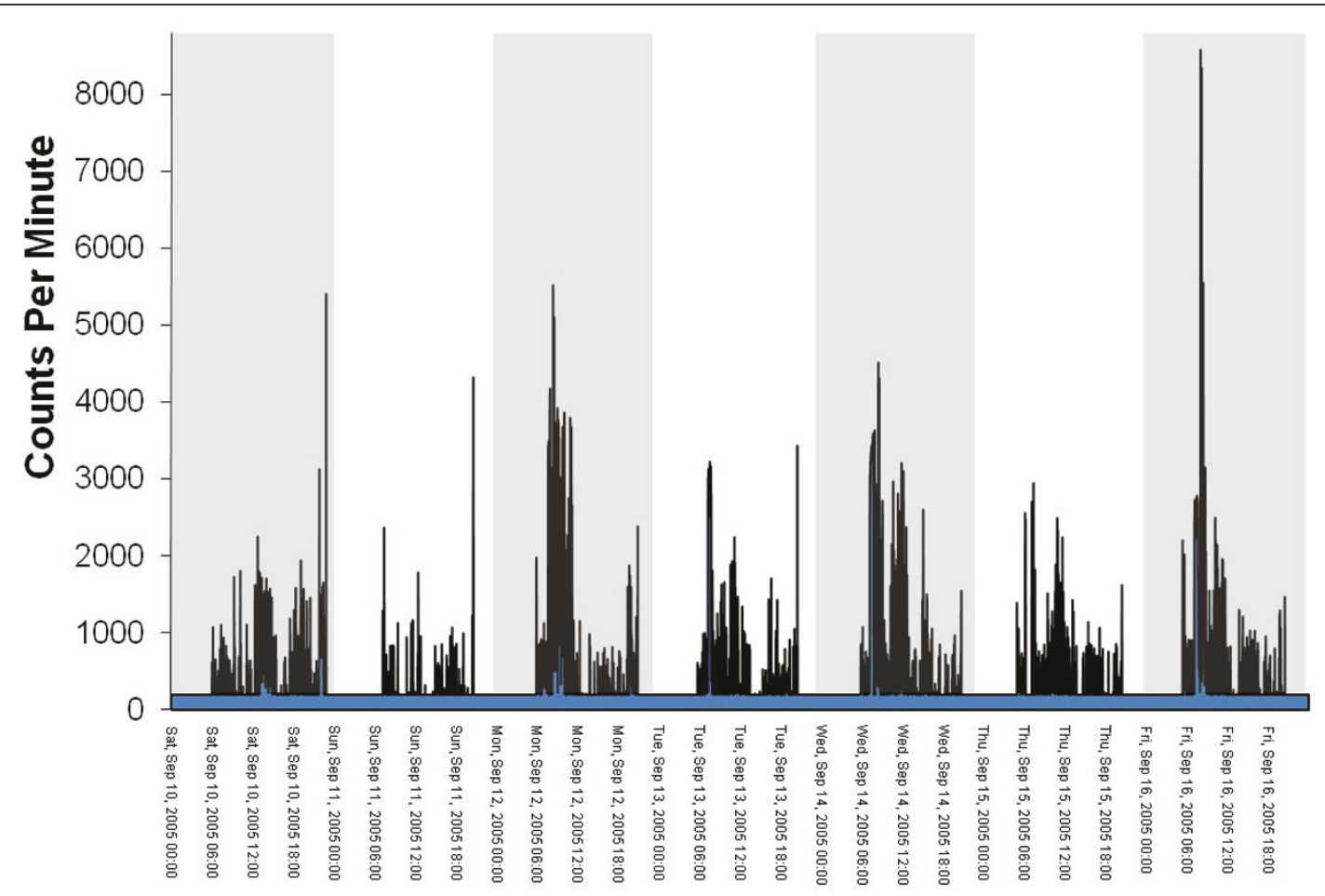

Figure 4 Graphical example of a potentially spurious file that does not return to baseline (zero)

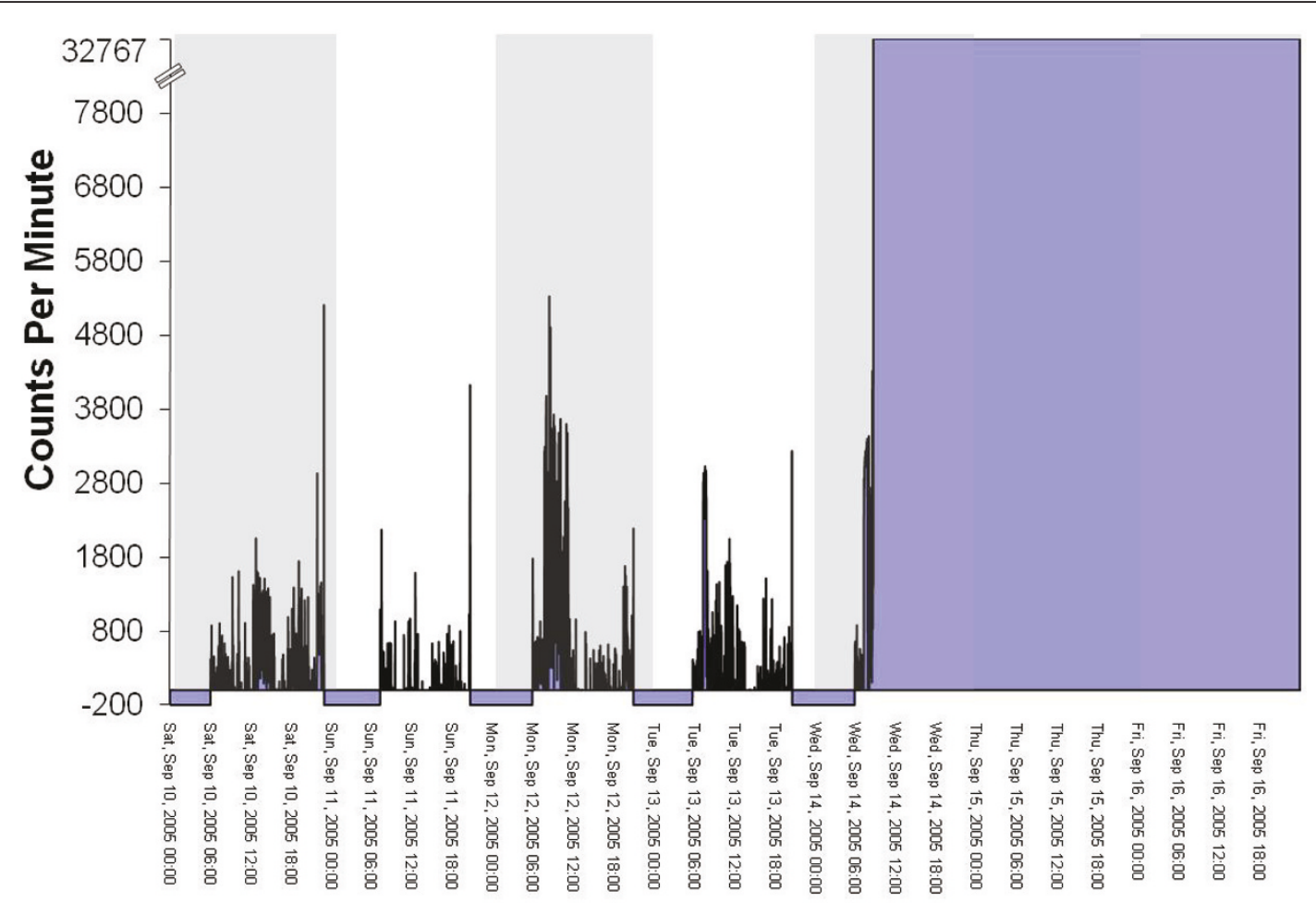

Figure 5 Graphical example of a file from a malfunctioned unit where the sensor voltage plateaus at saturation (32767 counts) 

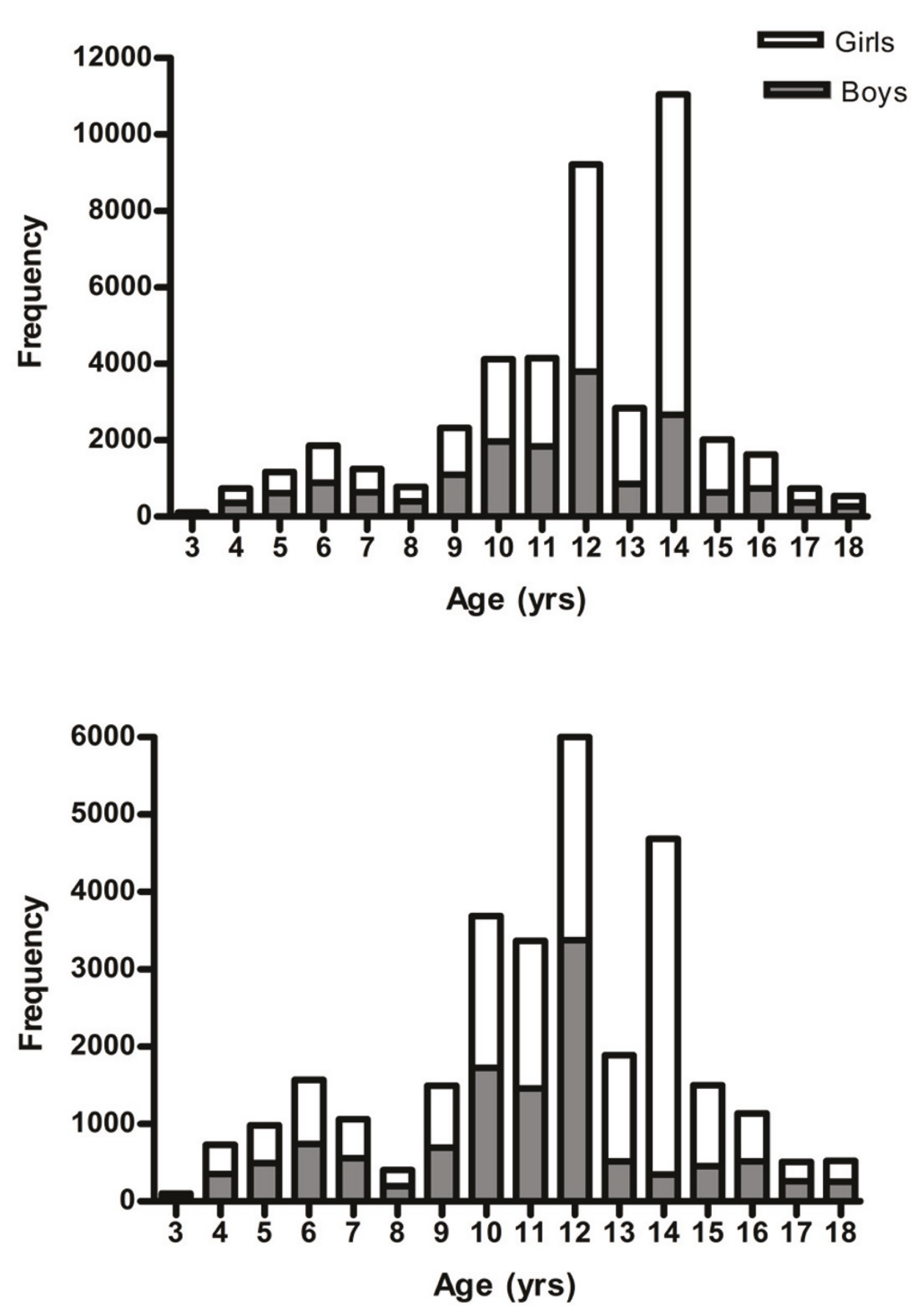

Figure 6 Sample size distribution; a) with repeated measures included; b) baseline only data.

\section{Nhanes}

Although data from the NHANES study are publically available, the raw Actigraph data are not. The data are only available in the Statistical Analysis Software (SAS) format and important aspects of the Actigraph file header, such as the serial number, initialization date, initialization time, download date, and download time, are not made available due to confidentiality concerns. Therefore, the SAS formatted, time-stamped count data was reconstituted into individual raw Actigraph. dat files with start times and epoch lengths of 00:00:00 and 60 seconds, respectively. Fortunately, NHANES used semiautomated initialization procedures so human errors were not possible. The file start dates were adjusted 
from January 1st thru 7th in order to maintain the correct day of the week of the reconstituted. dat files. The year of the start date was listed as 2004 for all files in the 2003-04 NHANES dataset and was listed as 2006 for all files in the 2005-06 NHANES dataset.

\section{Daylight Saving or Summer Time Event}

When Actigraph files spanned a daylight saving time (DST) or summer time event a simple data modeling tool was used to ensure all files would be compared equally. In the spring, when the clocks were set ahead, the missing hour of data was imputed based on the replication of the 30 minutes pre and post the event time. In the fall, when clocks were set back, the middle hour epoch was used only.

\section{Start dates}

The vast majority of Actigraph data files were initialized to collect data on day one of the instrument's deployment; however, in a minority of cases, Actigraphs were initialized prior to being deployed. In these cases, the start date and/or start time was altered using a read-infile with the file specific date and/or time exceptions. This analytical functionality was important as it allowed the studies to be processed in large batches.

\section{Physical activity outcome variables}

One frequently used accelerometer post-processing method involves the use of physical activity intensity thresholds (i.e., cutpoints based on count values) to summarize time spent in a given intensity category (e.g., sedentary, light, moderate and vigorous). There are many cutpoints that have been published for use with the Actigraph accelerometer [29,41-47]. At present there is no firm consensus regarding the optimal intensity cutpoints to use when analyzing the Actigraph data of children, adolescents or adults. However, a number of cutpoints have achieved a level of acceptability. In an effort to provide researchers with physical activity data derived from a range of Actigraph cutpoints, variables were derived using multiple cutpoints (see Additional file 2, Table S5). It is expected that as the database evolves, new cutpoints will be added as the field progresses.

How time spent in different intensities is accumulated will also be provided in ICAD. For example, MVPA accumulated in bouts lasting $0-10$ and $10+$ minutes will be provided in the database. For full listings of the bouts provided for each intensity see Additional file 2, Table S4. Furthermore, data (for all intensity variables) will be provided for specific windows of time. The analytical software was prompted to provide $1 \mathrm{hr}$ (on the hour) windows (hr1-hr24). In addition other windows of interest (determined by scrutinizing the literature and obtaining feedback from partners) were also provided, including before or after school periods, morning and afternoon commute, and lunch and recess time (see Additional file 2, Table S3). A data dictionary which provides a definition of all accelerometer variables in the ICAD database can be found at http://www.mrcepid.cam.ac.uk/Research/Studies/

\section{Results}

Among the males $96 \%, 93.5 \%$ and $86.2 \%$ had at least one valid day of data when using $\geq 8, \geq 10$ and $\geq 12$ hrs of wear as a criteria for a valid day (Table 2). Among the females $96.3 \%, 93.7 \%$ and $86 \%$ had at least one valid day of data when using $\geq 8, \geq 10$ and $\geq 12 \mathrm{hrs}$ of wear as a criteria for a valid day (Table 3). The number of valid days of data are less in the pre-school ages (3-5 years) as compared to the older ages (6-18 yrs), which can be partly explained by a shorter deployment time (2-5 days) among the pre-school studies.

\section{Discussion}

\section{Selection of studies}

In terms of meta-analyses it is necessary to include all relevant studies, or at least a representative sample, of which only clearly flawed studies or studies with small

Table 2 Percentage of male respondents, by valid days of accelerometer wear (using $\geq 8, \geq 10$ and $\geq 12$ hours of wear as criteria) and age group

\begin{tabular}{|c|c|c|c|c|c|c|c|c|c|c|}
\hline & \multicolumn{10}{|c|}{ Number of valid days } \\
\hline & 0 & 1 & 2 & 3 & 4 & 5 & 6 & 7 & $\geq 1$ & $\geq 4$ \\
\hline \multicolumn{11}{|l|}{3 to 5} \\
\hline$\geq 8 \mathrm{hrs}$ & 5.7 & 8.2 & 19.8 & 25.5 & 23.1 & 8.5 & 8.1 & 1.1 & 94.3 & 40.8 \\
\hline$\geq 10 \mathrm{hrs}$ & 10.4 & 12.7 & 23.1 & 25.9 & 18.5 & 5.4 & 3.8 & 0.2 & 89.6 & 28.0 \\
\hline$\geq 12 \mathrm{hrs}$ & 27.8 & 23.6 & 22.2 & 18.1 & 6.9 & 1.2 & 0.1 & 0.2 & 72.2 & 8.3 \\
\hline \multicolumn{11}{|l|}{6 to 8} \\
\hline$\geq 8$ hrs & 2.9 & 3.4 & 5.3 & 9.7 & 33.0 & 11.8 & 16.3 & 17.7 & 97.1 & 78.7 \\
\hline$\geq 10$ hrs & 4.9 & 5.7 & 8.1 & 15.6 & 29.3 & 10.2 & 13.1 & 13.1 & 95.1 & 65.7 \\
\hline$\geq 12 \mathrm{hrs}$ & 11.1 & 13.3 & 18.7 & 17.9 & 16.6 & 8.8 & 5.7 & 7.9 & 88.9 & 39.0 \\
\hline \multicolumn{11}{|l|}{9 to 11} \\
\hline$\geq 8 \mathrm{hrs}$ & 1.5 & 2.5 & 4.4 & 9.0 & 29.2 & 20.0 & 20.9 & 12.5 & 98.5 & 82.6 \\
\hline$\geq 10 \mathrm{hrs}$ & 2.7 & 3.9 & 6.4 & 12.9 & 29.6 & 18.9 & 16.9 & 8.6 & 97.3 & 74.0 \\
\hline$\geq 12 \mathrm{hrs}$ & 6.3 & 8.1 & 14.8 & 21.7 & 23.1 & 13.3 & 8.2 & 4.4 & 93.7 & 49.1 \\
\hline \multicolumn{11}{|l|}{12 to14 } \\
\hline$\geq 8$ hrs & 3.7 & 2.9 & 3.6 & 6.2 & 11.5 & 19.2 & 18.9 & 34.0 & 96.3 & 83.6 \\
\hline$\geq 10 \mathrm{hrs}$ & 5.5 & 3.7 & 5.6 & 8.9 & 14.2 & 18.8 & 19.0 & 24.4 & 94.6 & 76.4 \\
\hline$\geq 12 \mathrm{hrs}$ & 8.9 & 7.2 & 9.2 & 12.5 & 19.0 & 17.5 & 15.8 & 9.9 & 91.1 & 62.2 \\
\hline \multicolumn{11}{|l|}{15 to 18} \\
\hline$\geq 8 \mathrm{hrs}$ & 6.0 & 5.6 & 6.7 & 10.9 & 19.1 & 17.0 & 18.5 & 16.2 & 94.0 & 70.7 \\
\hline$\geq 10 \mathrm{hrs}$ & 9.2 & 7.4 & 9.4 & 12.6 & 18.9 & 17.4 & 14.4 & 10.7 & 90.8 & 61.4 \\
\hline$\geq 12 \mathrm{hrs}$ & 14.8 & 11.0 & 12.4 & 16.2 & 16.6 & 13.3 & 9.8 & 5.8 & 85.2 & 45.5 \\
\hline \multicolumn{11}{|l|}{ Overall } \\
\hline $8 \mathrm{hrs}$ & 3.9 & 4.5 & 8.0 & 12.3 & 23.2 & 15.3 & 16.5 & 16.3 & 96.0 & 71.3 \\
\hline $10 \mathrm{hrs}$ & 6.6 & 6.7 & 10.5 & 15.2 & 22.1 & 14.2 & 13.4 & 11.4 & 93.5 & 61.1 \\
\hline $12 \mathrm{hrs}$ & 13.8 & 12.6 & 15.5 & 17.3 & 16.5 & 10.8 & 7.9 & 5.6 & 86.2 & 40.8 \\
\hline
\end{tabular}


Table 3 Percentage of female respondents, by valid days of accelerometer wear (using $\geq 8, \geq 10$ and $\geq 12$ hours of wear as criteria) and age group

\begin{tabular}{|c|c|c|c|c|c|c|c|c|c|c|}
\hline & \multicolumn{10}{|c|}{ Number of valid days } \\
\hline & 0 & 1 & 2 & 3 & 4 & 5 & 6 & 7 & $\geq 1$ & $\overline{\geq 4}$ \\
\hline \multicolumn{11}{|l|}{3 to 5} \\
\hline$\geq 8 \mathrm{hrs}$ & 7.7 & 8.6 & 20.8 & 19.9 & 25.0 & 9.0 & 8.4 & 0.7 & 92.3 & 43.1 \\
\hline$\geq 10 \mathrm{hrs}$ & 12.8 & 11.9 & 24.3 & 21.2 & 21.1 & 5.0 & 3.4 & 0.3 & 87.2 & 29.8 \\
\hline$\geq 12 \mathrm{hrs}$ & 30.6 & 23.2 & 24.0 & 14.0 & 6.6 & 1.0 & 0.4 & 0.1 & 69.3 & 8.1 \\
\hline \multicolumn{11}{|l|}{6 to 8} \\
\hline $8 \mathrm{hrs}$ & 2.3 & 3.1 & 5.8 & 9.7 & 31.3 & 13.7 & 15.5 & 18.6 & 97.7 & 79.2 \\
\hline$\geq 10 \mathrm{hrs}$ & 4.4 & 5.0 & 10.3 & 14.2 & 29.5 & 10.6 & 11.7 & 14.2 & 95.6 & 66.1 \\
\hline$\geq 12 \mathrm{hrs}$ & 11.6 & 12.8 & 17.7 & 19.5 & 15.8 & 7.2 & 6.0 & 9.4 & 88.5 & 38.4 \\
\hline \multicolumn{11}{|l|}{9 to 11} \\
\hline$\geq 8$ hrs & 1.0 & 1.9 & 3.8 & 8.2 & 29.0 & 19.7 & 22.8 & 13.6 & 99.0 & 85.1 \\
\hline$\geq 10 \mathrm{hrs}$ & 1.9 & 3.2 & 6.5 & 12.8 & 29.5 & 19.7 & 17.9 & 8.6 & 98.1 & 75.6 \\
\hline$\geq 12 \mathrm{hrs}$ & 5.2 & 8.3 & 14.8 & 20.6 & 24.8 & 14.5 & 8.0 & 3.9 & 94.8 & 51.1 \\
\hline \multicolumn{11}{|l|}{12 to 14} \\
\hline$\geq 8 \mathrm{hrs}$ & 2.6 & 3.2 & 4.3 & 7.8 & 11.8 & 18.3 & 24.8 & 27.1 & 97.4 & 82.0 \\
\hline$\geq 10 \mathrm{hrs}$ & 4.3 & 4.7 & 6.6 & 9.9 & 15.7 & 19.3 & 22.6 & 16.8 & 95.7 & 74.4 \\
\hline$\geq 12 \mathrm{hrs}$ & 7.6 & 8.3 & 10.3 & 14.5 & 19.2 & 18.8 & 15.2 & 6.2 & 92.4 & 59.3 \\
\hline \multicolumn{11}{|l|}{15 to 18} \\
\hline$\geq 8$ hrs & 5.2 & 6.4 & 6.3 & 9.6 & 19.2 & 19.4 & 19.0 & 15.1 & 94.9 & 72.6 \\
\hline$\geq 10 \mathrm{hrs}$ & 8.0 & 9.0 & 9.0 & 12.9 & 20.5 & 15.3 & 16.3 & 9.1 & 92.0 & 61.1 \\
\hline$\geq 12 \mathrm{hrs}$ & 14.8 & 11.2 & 13.0 & 16.3 & 18.0 & 13.4 & 9.3 & 4.1 & 85.2 & 44.7 \\
\hline \multicolumn{11}{|l|}{ Overall } \\
\hline $8 \mathrm{hrs}$ & 3.8 & 4.6 & 8.2 & 11.0 & 23.3 & 16.0 & 18.1 & 15.0 & 96.3 & 72.4 \\
\hline 10 hrs & 6.3 & 6.8 & 11.3 & 14.2 & 23.3 & 14.0 & 14.4 & 9.8 & 93.7 & 61.4 \\
\hline $12 \mathrm{hrs}$ & 14.0 & 12.8 & 16.0 & 17.0 & 16.9 & 11.0 & 7.8 & 4.7 & 86.0 & 40.3 \\
\hline
\end{tabular}

sample size are omitted. These same sampling considerations could be applied to this study. However, although a large number of studies have contributed to ICAD, some smaller studies and studies that had not published any findings on PubMed may have been missed.

\section{Variability between studies}

As previously mentioned, an obvious advantage of pooling accelerometer data is a very practical one: to increase sample size. However, this comes at a price: in comparison to a single large-scale study, ICAD will have inflated variability in its accelerometer measurements. This is because, although much variability is reduced by the utilization of standardized analytical techniques, variation in the deployment strategies used between contributing studies can generate significant between-study variability in accelerometer outputs. One potential cause of between-study variability is the use of different models (i.e. generations) of the Actigraph. In fact Rothney et al. 2008 [48] found differences in the outputs from the
7164 and the GT1M monitors when undergoing mechanical testing. Unfortunately, understanding these differences is hampered by the fact that the unlike the Actigraph 7164 (see [23]) there is no published paper detailing the specifications of the Actigraph GT1M. Fortunately, recent studies [28,49-51] provide insight into technical specifications of the GT1M. Despite the between model differences in the Actigraph, studies in free-living individuals showed that during self-paced locomotion at a range of speeds, the different Actigraph models did not result in meaningful differences in the classification of physical activity intensity [50] or activity count output [49]. Increased variability could also be caused by variation in the season (e.g. spring, summer, winter, fall) in which the accelerometer was worn $[52,53]$.

The above limitations notwithstanding, the increased variability in ICAD can be considered a real advantage. For example, the main strength of the pooled ICAD database is its enhanced social and cultural diversity, compared to any of the individual studies. The investigation of the influence of these socio-cultural influences may lead to new insights into how children's physical activity patterns are shaped. Furthermore, including participants from a variety of geographical locations may lead to further insights into the possible influence of the physical environment. Lastly, analysis of pooled data can be useful to quantitatively examine the generalizability of findings. For example, findings that are replicated across individual studies carry increased validity, as they are more likely to be linked to the research question being addressed than to differences in study design and data collection procedures (such as different climatic zones, different seasons, different days of the week, different number of days of deployment, etc.).

\section{Non-accelerometer data}

Unfortunately, with the large variation in the tools used to assess nutrition and psychological constructs, these data are not suitable for pooling and were not collected. This is a limitation of the database. If repositories of accelerometer data become more mainstream investigators may see added benefit of considering measures that are consistent between large studies (as seen in recent projects such as the Public Population Project in Genomics (P3G) [54]). Furthermore, this may accelerate the work aimed at equalizing scales and measures, thus enabling analysis of nutrition and psychological data, as it relates to physical activity, in the future.

\section{Data Availability}

The ICAD partners (i.e. contributors of the data) have sole access to the pooled database for 12 months (March 2011-Feb 2012), after which time the database is 
open to any approved user (see http://www.mrc-epid. cam.ac.uk/Research/Studies/ for more information on the procedures for using ICAD).

\section{Conclusions}

Increasing physical activity levels in those insufficiently active is a complex and long term issue. We currently do not have sufficient evidence to design effective physical activity interventions that will result in long-term behaviour change. In essence, we do not know the full range of determinants of physical activity, nor do we have sufficient knowledge of how different levels and patterns of activity are associated with physiological and psychological health outcomes. Public health requires a more substantial and comprehensive understanding of this complex behavior [55]. Pooling objective measurements of physical activity and accompanying physiological, demographic and health data from diverse studies in contrasting settings maximizes analytical power and provides new evidence on potential social, cultural and environmental influences on behaviour. Such a database can potentially give important insights into physical activity and health inequalities. It is hoped that ICAD will be a valuable resource for researchers, policy makers and practitioners, in their search for evidence, as well as less senior researchers and students who might use the resource as part of their training program. We hope that the ICAD database will be further developed so that new accelerometer studies can be added (for example studies of adults) and become a publically available archive.

\section{Footnotes}

${ }^{1}$ Note: The most recent Actigraph model (the GT3X) had not been released at the time data were deposited

${ }^{2}$ None of the GT1M accelerometers used in ICAD underwent the firmware update to activate the second (i.e. dual) axis which was introduced as an option in 2008

\section{Additional material}

Additional file 1: Non-Accelerometer Variables included in the International Children's Accelerometer Database (ICAD)

Additional file 2: Accelerometer Variables included in the International Children's Accelerometer Database (ICAD) [84-86].

\section{Acknowledgements and funding}

Contributors of data to the International Children's Accelerometry Database (ICAD) include: Avon Longitudinal Study of Parents and Children (ALSPAC: Dr. A. Ness), Ballabeina Study (Dr. P.P. Puder); Belgium Pre-School Study (Dr. G. Cardon); Children's Health and Activity Monitoring for Schools (CHAMPS; Dr. R. Davey); Physical Activity in Pre-school Children (Dr. R. Pate); Children Living in Active Neigbourhoods CLAN; Dr. J. Salmon); Copenhagen School
Child Intervention Study (CSCIS; Dr. L. Bo-Anderson); European Youth Heart Study (EYHS), Denmark (Dr. K Froberg), Portugal (Prof. Luis Sardinha), Norway (Dr. S. Anderssen); Healthy Eating and Play Study (HEAPS; Dr. J. Salmon); lowa Bone Development Study (Dr. K.F. Janz); Kinder-Sportstudie (KISS) Study (Dr. S. Kreimler); Movement and Activity Glasgow Intervention in Children (MAGIC; Dr. J. Reilly); National Health and Nutrition Examination Survey (NHANES; 03/04; 05/06; Centers for Disease Control and Prevention (CDC). National Center for Health Statistics (NCHS). Hyattsville, MD USA). Personal and Environmental Associations with Children's Health (PEACH; Dr. A. Cooper); 1993 Pelotas Birth Cohort (Dr. P. Hallal); Project Trial of Activity for Adolescent Girls (Project TAAG; Dr. R. Pate); Sport, Physical activity and Eating behavior: Environmental Determinants in Young people (SPEEDY) Study (Dr. U. Ekelund).

Funding for the project was provided by the National Preventative Research Initiative (NPRl; http://www.npri.org.uk). Funding partners are: British Heart Foundation; Cancer Research UK; Department of Health; Diabetes UK: Economic and Social Research Council; Medical Research Council; Research and Development Office for the Northern Ireland Health and Social Services; Chief Scientist Office, Scottish Executive Health Department; The Stroke Association; Welsh Assembly Government and World Cancer Research Fund.

\section{Author details}

${ }^{1}$ College of Kinesiology, University of Saskatchewan, Saskatoon, SK, Canada. ${ }^{2}$ School of Sport and Health Sciences, University of Exeter, Heavitree Road, Exeter, UK. ${ }^{3}$ Exercise, Nutrition and Health Sciences, School for Policy Studies, University of Bristol, Bristol, UK. ${ }^{4}$ Medical Research Council Epidemiology Unit, Cambridge, UK. ${ }^{5}$ School of Health and Medical Sciences, Örebro University, Örebro, Sweden. ${ }^{6}$ Department for Health, University of Bath, Bath, UK.

\section{Authors' contributions}

LBS recruited studies, cleaned and reduced the raw accelerometer data to the outcome variables, wrote the first draft of the manuscript and developed Additional file 2. PG organized the transfer of data, compiled and re-coded the non-accelerometer variables, merged data to form the final database and developed Additional file 1. DWE consulted on accelerometer data reduction and helped draft the manuscript. AC and UE contributed to the conceiving the project, participated in the design and coordination of the project and in the reduction of the data. $\mathrm{KJ}$ participated in the design and coordination of the project and consulted in re-coding the sociodemographic data. CR contributed to the conceiving of the project, coordinated the project, participated in its design and helped to draft the manuscript. All authors read and approved the final manuscript.

\section{Competing interests}

Dale Esliger is the owner and founder of KineSoft, the accelerometer data analysis software used for the creation of the accelerometer outcome variables deposited in the ICAD.

Received: 4 April 2011 Accepted: 21 June 2011 Published: 21 June 2011

\section{References}

1. Department of Health and Human Services: Physical activity and health: $A$ report of the surgeon general. Atlanta, GA, DHHS\&CDCP; 1996.

2. Strong WB, Malina RM, Blimkie CJ, Daniels SR, Dishman RK, Gutin B, Hergenroeder AC, Must A, Nixon PA, Pivarnik JM, Rowland T, Trost S, Trudeau F: Evidence based physical activity for school-age youth. $J$ Pediatr 2005, 146:732-737.

3. Bailey RC, Olson J, Pepper SL, Porszasz J, Barstow TJ, Cooper DM: The level and tempo of children's physical activities: an observational study. Med Sci Sports Exerc 1995, 27:1033-1041.

4. Baquet G, Stratton G, Van Praagh E, Berthoin S: Improving physical activity assessment in prepubertal children with high-frequency accelerometry monitoring: a methodological issue. Prev Med 2007, 44:143-147.

5. Berman M, Bailey R, Barstow TJ, Cooper DM: Spectral and Bout Detection Analysis of Physical Activity Patterns in Healthy, Prepubertal Boys and Girls. Am J Hum Biol 1998, 10:289-297.

6. Owen CG, Nightingale CM, Rudnicka AR, Sattar N, Cook DG, Ekelund U, Whincup PH: Physical activity, obesity and cardiometabolic risk factors in 9- to 10-year-old UK children of white European, South Asian and black 
African-Caribbean origin: the Child Heart And health Study in England (CHASE). Diabetologia 2010, 53:1620-1630.

7. Steele RM, van Sluijs EM, Cassidy A, Griffin SJ, Ekelund U: Targeting sedentary time or moderate- and vigorous-intensity activity: independent relations with adiposity in a population-based sample of 10-y-old British children. Am J Clin Nutr 2009, 90:1185-1192.

8. Mark $A E$, Janssen I: Influence of bouts of physical activity on overweight in youth. Am J Prev Med 2009, 36:416-421.

9. Mark $A E$, Janssen I: Dose-response relation between physical activity and blood pressure in youth. Med Sci Sports Exerc 2008, 40:1007-1012.

10. Hopkins ND, Stratton G, Tinken TM, McWhannell N, Ridgers ND, Graves LE, George K, Cable NT, Green DJ: Relationships between measures of fitness, physical activity, body composition and vascular function in children. Atherosclerosis 2009, 204:244-249.

11. Dencker M, Andersen LB: Health-related aspects of objectively measured daily physical activity in children. Clin Physiol Funct Imaging 2008, 28:133-144.

12. LeBlanc $A G$, Janssen I: Dose-response relationship between physical activity and dyslipidemia in youth. Can J Cardiol 2010, 26:201-205.

13. Riddoch CJ, Leary SD, Ness AR, Blair SN, Deere K, Mattocks C, Griffiths A, Davey SG, Tilling K: Prospective associations between objective measures of physical activity and fat mass in 12-14 year old children: the Avon Longitudinal Study of Parents and Children (ALSPAC). Br Med J 2009, 339 b4544.

14. Andersen LB, Harro M, Sardinha LB, Froberg K, Ekelund U, Brage S, Anderssen SA: Physical activity and clustered cardiovascular risk in children: a cross-sectional study (The European Youth Heart Study). Lancet 2006, 368:299-304.

15. Ness AR, Leary SD, Mattocks C, Blair SN, Reilly JJ, Wells J, Ingle S, Tilling K, Smith GD, Riddoch C: Objectively Measured Physical Activity and Fat Mass in a Large Cohort of Children. PLoS Med 2007, 4:e97.

16. Tobias JH, Steer CD, Mattocks CG, Riddoch C, Ness AR: Habitual levels of physical activity influence bone mass in 11-year-old children from the United Kingdom: findings from a large population-based cohort. J Bone Miner Res 2007, 22:101-109.

17. Mattocks C, Deere K, Leary S, Ness A, Tilling K, Blair SN, Riddoch C: Early life determinants of physical activity in 11 to 12 year olds: cohort study. $\mathrm{Br} J$ Sports Med 2008, 42:721-724.

18. Scott MM, Evenson KR, Cohen DA, Cox CE: Comparing perceived and objectively measured access to recreational facilities as predictors of physical activity in adolescent girls. J Urban Health 2007, 84:346-359.

19. Morgan PJ, Okely AD, Cliff DP, Jones RA, Baur LA: Correlates of objectively measured physical activity in obese children. Obesity (Silver Spring) 2008, 16:2634-2641.

20. van Sluijs EM, Fearne VA, Mattocks C, Riddoch C, Griffin SJ, Ness A: The contribution of active travel to children's physical activity levels: crosssectional results from the ALSPAC study. Prev Med 2009, 48:519-524.

21. Crawford D, Cleland V, Timperio A, Salmon J, Andrianopoulos N, Roberts R, Giles-Corti B, Baur L, Ball K: The longitudinal influence of home and neighbourhood environments on children's body mass index and physical activity over 5 years: the CLAN study. Int J Obes (Lond) 2010, 34:1177-1187.

22. Kwon S, Janz KF, Burns TL, Levy SM: Effects of Adiposity on Physical Activity in Childhood: lowa Bone Development Study. Med Sci Sports Exerc 2010, 43:443-448.

23. Tyron WW, Williams R: Fully proportional actigraphy: a new instrument. Behav Research Methods Instruments Comput 1996, 28:392-403.

24. Esliger DW, Tremblay MS: Physical activity and inactivity profiling: the next generation. Can J Public Health 2007, 98(Suppl 2):S195-S207.

25. Esliger DW, Tremblay MS: Technical reliability assessment of three accelerometer models in a mechanical setup. Med Sci Sports Exerc 2006, 38:2173-2181.

26. Brage S, Wedderkopp N, Franks PW, Andersen LB, Froberg K: Reliability and validity of the computer science and applications accelerometer in a mechanical setting. Measurement in Physical Education and Exercise 2003, 7:101-119

27. Metcalf BS, Curnow JS, Evans C, Voss LD, Wilkin TJ: Technical reliability of the CSA activity monitor: The EarlyBird Study. Med Sci Sports Exerc 2002, 34:1533-1537.
28. Silva P, Mota J, Esliger D, Welk G: Technical reliability assessment of the Actigraph GT1M Accelerometer. Measurement in Physical Education and Exercise 2010, 14:79-91

29. Sirard JR, Melanson EL, Li L, Freedson PS: Field evaluation of the Computer Science and Applications, Inc. physical activity monitor. Med Sci Sports Exerc 2000, 32:695-700.

30. Ekelund U, Sjostrom M, Yngve A, Poortvliet E, Nilsson A, Froberg K, Wedderkopp N, Westerterp K: Physical activity assessed by activity monitor and doubly labeled water in children. Med Sci Sports Exerc 2001, 33:275-281.

31. Victora CG, Hallal PC, Araujo CL, Menezes AM, Wells JC, Barros FC: Cohort profile: the 1993 Pelotas (Brazil) birth cohort study. Int J Epidemiol 2008, 37:704-709.

32. Reichert FF, Menezes AM, Kingdom Wells JC, Ekelund E, Rodrigues FM, Hallal PC: A methodological model for collecting high-quality data on physical activity in developing settings-the experience of the 1993 Pelotas (Brazil) Birth Cohort study. J Phys Act Health 2009, 6:360-366.

33. Victora CG, Araujo CL, Menezes AM, Hallal PC, Vieira MF, Neutzling MB, Goncalves H, Valle NC, Lima RC, Anselmi L, Behague D, Gigante DP, Barros FC: Methodological aspects of the 1993 Pelotas (Brazil) Birth Cohort Study. Rev Saude Publica 2006, 40:39-46.

34. Gabriel KP, McClain JJ, Schmid KK, Storti KL, High RR, Underwood DA, Kuller LH, Kriska AM: Issues in accelerometer methodology: the role of epoch length on estimates of physical activity and relationships with health outcomes in overweight, post-menopausal women. Int J Behav Nutr Phys Act 2010, 7:53.

35. Vale S, Santos R, Silva P, Soares-Miranda L, Mota J: Preschool children physical activity measurement: importance of epoch length choice. Pediatr Exerc Sci 2009, 21:413-420.

36. McClain JJ, Abraham TL, Brusseau TA Jr, Tudor-Locke C: Epoch length and accelerometer outputs in children: comparison to direct observation. Med Sci Sports Exerc 2008, 40:2080-2087.

37. Edwardson $\mathrm{CL}$, Gorely $\mathrm{T}$ : Epoch length and its effect on physical activity intensity. Med Sci Sports Exerc 2010, 42:928-934.

38. Corder K, Brage S, Ramachandran A, Snehalatha C, Wareham N, Ekelund U: Comparison of two Actigraph models for assessing free-living physical activity in Indian adolescents. J Sports Sci 2007, 25:1607-1611.

39. Nilsson A, Ekelund U, Yngve A, Sjostrom M: Assessing physical activity among children with accelerometers using different time sampling intervals and placements. Pediatr Exerc Sci 2002, 14:87-96.

40. Rowlands AV, Powell SM, Humpreys R, Eston RG: The effect of accelerometer epoch on physical activity output measures. Journal of Exercise Science and Fitness 2006, 4:52-58.

41. Rothney MP, Brychta RJ, Meade NN, Chen KY, Buchowski MS: Validation of the ActiGraph two-regression model for predicting energy expenditure. Med Sci Sports Exerc 2010, 42:1785-1792.

42. Puyau MR, Adolph AL, Vohra FA, Butte NF: Validation and calibration of physical activity monitors in children. Obes Res 2002, 10:150-157.

43. Pate RR, Almeida MJ, Mclver KL, Pfeiffer KA, Dowda M: Validation and calibration of an accelerometer in preschool children. Obesity (Silver Spring) 2006, 14:2000-2006

44. Reilly JJ, Coyle J, Kelly L, Burke G, Grant S, Paton JY: An objective method for measurement of sedentary behavior in 3- to 4-year olds. Obes Res 2003, 11:1155-1158.

45. Treuth MS, Schmitz K, Catellier DJ, McMurray RG, Murray DM, Almeida MJ, Going S, Norman JE, Pate R: Defining accelerometer thresholds for activity intensities in adolescent girls. Med Sci Sports Exerc 2004, 36:1259-1266.

46. Mattocks C, Leary S, Ness A, Deere K, Saunders J, Tilling K, Kirkby J, Blair SN, Riddoch C: Calibration of an accelerometer during free-living activities in children. Int J Pediatr Obes 2007, 2:218-226.

47. Evenson KR, Catellier DJ, Gill K, Ondrak KS, McMurray RG: Calibration of two objective measures of physical activity for children. J Sports Sci 2008, 26:1557-1565.

48. Rothney MP, Apker GA, Song Y, Chen KY: Comparing the performance of three generations of ActiGraph accelerometers. J Appl Physiol 2008, 105:1091-1097

49. John D, Tyo B, Bassett DR: Comparison of four ActiGraph accelerometers during walking and running. Med Sci Sports Exerc 2010, 42:368-374. 
50. Kozey SL, Staudenmayer JW, Troiano RP, Freedson PS: Comparison of the ActiGraph 7164 and the ActiGraph GT1M during self-paced locomotion. Med Sci Sports Exerc 2010, 42:971-976.

51. van Hees VT, Pias M, Taherian S, Ekelund U, Brage S: A method to compare new and traditional accelerometry data in physical activity monitoring. Proc of the 2nd IEEE International WoWMOM Workshop on Interdisciplinary Research on E-Health Services and Systems (IREHSS), Montreal, Canada, June, 2010

52. Kolle E, Steene-Johannessen J, Andersen LB, Anderssen SA: Seasonal variation in objectively assessed physical activity among children and adolescents in Norway: a cross-sectional study. Int J Behav Nutr Phys Act 2009, 6:36

53. Rowlands AV, Pilgrim EL, Eston RG: Seasonal changes in children's physical activity: an examination of group changes, intra-individual variability and consistency in activity pattern across season. Ann Hum Biol 2009, 36:363-378.

54. Knoppers BM, Fortier I, Legault D, Burton P: The Public Population Project in Genomics (P3G): a proof of concept? Eur J Hum Genet 2008, 16:664-665.

55. Lagerros YT: Physical activity-the more we measure, the more we know how to measure. Eur J Epidemiol 2009, 24:119-122.

56. Golding J, Pembrey M, Jones R: ALSPAC-the Avon Longitudinal Study of Parents and Children. I. Study methodology. Paediatr Perinat Epidemiol 2001, 15:74-87.

57. Niederer I, Kriemler S, Zahner L, Burgi F, Ebenegger V, Hartmann T, Meyer U, Schindler C, Nydegger A, Marques-Vidal P, Puder JJ: Influence of a lifestyle intervention in preschool children on physiological and psychological parameters (Ballabeina): study design of a cluster randomized controlled trial. BMC Public Health 2009, 9:94.

58. Cardon G, Labarque V, Smits D, De B I: Promoting physical activity at the pre-school playground: the effects of providing markings and play equipment. Prev Med 2009, 48:335-340.

59. Cardon G, De B I: Comparison of pedometer and accelerometer measures of physical activity in preschool children. Pediatr Exerc Sci 2007, 19:205-214.

60. Van Cawenberghe E, Labarque V, Trowbridge C, De Bourdeaudhuij I, Cardon G: Calibration and Comparison of Accelerometer Cut Points in Preschool Children. International Journal of Pediatric Obesity 2010.

61. Gidlow CJ, Cochrane T, Davey R, Smith H: In-school and out-of-school physical activity in primary and secondary school children. J Sports Sci 2008, 26:1411-1419.

62. Smith H, Grogan S, Davey R, Cochrane T: Developing a successful physical activity intervention in primary school children. Education and Health 2009, 27:63-66.

63. Pfeiffer KA, Dowda M, Mclver KL, Pate RR: Factors related to objectively measured physical activity in preschool children. Pediatr Exerc Sci 2009, 21:196-208.

64. Telford A, Salmon J, Timperio A, Crawford D: Examining physical activity among 5- to 6- and 10- to 12-year old children: the Children's Leisure Activities Study. Pediatr Exerc Sci 2005, 17:266-280.

65. Timperio A, Ball K, Salmon J, Roberts R, Giles-Corti B, Simmons D, Baur LA, Crawford D: Personal, family, social, and environmental correlates of active commuting to school. Am J Prev Med 2006, 30:45-51.

66. Eiberg S, Hasselstrom H, Gronfeldt V, Froberg K, Svensson J, Andersen LB: Maximum oxygen uptake and objectively measured physical activity in Danish children 6-7 years of age: the Copenhagen school child intervention study. Br J Sports Med 2005, 39:725-730.

67. Hasselstrom H, Karlsson KM, Hansen SE, Gronfeldt V, Froberg K, Andersen LB: Peripheral bone mineral density and different intensities of physical activity in children 6-8 years old: the Copenhagen School Child Intervention study. Calcif Tissue Int 2007, 80:31-38.

68. Brage S, Wedderkopp N, Ekelund U, Franks PW, Wareham NJ, Andersen LB, Froberg K: Features of the metabolic syndrome are associated with objectively measured physical activity and fitness in Danish children: the European Youth Heart Study (EYHS). Diabetes Care 2004, 27:2141-2148.

69. Riddoch C, Edwards S, Page AS, Froberg K, Ando S, Wedderkopp N, Brage S, Cooper AR, Sardinha LB, Harro M, Heggebø LK, Mechelen WVBC, Ekelund U, Andersen LB: The European Youth Heart Study cardiovascular disease risk factors in children: rationale, aims, study design and validation of methods. Journal of Physical Activity and Health 2005, 2:115-129.
70. Jackson M, Crawford D, Campbell K, Salmon J: Are parental concerns about children's inactivity warranted, and are they associated with a supportive home environment? Res Q Exerc Sport 2008, 79:274-282.

71. Salmon J, Campbell KJ, Crawford DA: Television viewing habits associated with obesity risk factors: a survey of Melbourne schoolchildren. Med J Aust 2006, 184:64-67.

72. Janz KF, Burns TL, Torner JC, Levy SM, Paulos R, Willing MC, Warren JJ: Physical activity and bone measures in young children: the lowa bone development study. Pediatr 2001, 107:1387-1393.

73. Janz KF, Gilmore JM, Burns TL, Levy SM, Torner JC, Willing MC, Marshall TA: Physical activity augments bone mineral accrual in young children: The lowa Bone Development study. J Pediatr 2006, 148:793-799.

74. Zahner L, Puder JJ, Roth R, Schmid M, Guldimann R, Puhse U, Knopfli M, Braun-Fahrlander C, Marti B, Kriemler S: A school-based physical activity program to improve health and fitness in children aged 6-13 years ("Kinder-Sportstudie KISS"): study design of a randomized controlled trial [ISRCTN15360785]. BMC Public Health 2006, 6:147.

75. Reilly JJ, Kelly L, Montgomery C, Williamson A, Fisher A, McColl JH, Lo CR, Paton JY, Grant S: Physical activity to prevent obesity in young children: cluster randomised controlled trial. Br Med J 2006, 333:1041.

76. Centers for Disease Control and Prevention. Chapter 6: National Health and Nutrition Examination Survey (NHANES) Anthropometry and Physical Activity Monitor Procedures Manual. 2005.

77. Centers for Disease Control and Prevention. Chapter 16: National Health and Nutrition Examination Survey, Laboratory Procedures Manual. 2010

78. Ommundsen Y, Klasson-Heggebo L, Anderssen SA: Psycho-social and environmental correlates of location-specific physical activity among 9and 15-year-old Norwegian boys and girls: the European Youth Heart Study. Int J Behav Nutr Phys Act 2006, 3:32.

79. Page AS, Cooper AR, Griew P, Davis L, Hillsdon M: Independent mobility in relation to weekday and weekend physical activity in children aged 1011 years: The PEACH Project. Int J Behav Nutr Phys Act 2009, 6:2.

80. Sardinha LB, Andersen LB, Anderssen SA, Quiterio AL, Ornelas R, Froberg K, Riddoch CJ, Ekelund U: Objectively measured time spent sedentary is associated with insulin resistance independent of overall and central body fat in 9- to 10-year-old Portuguese children. Diabetes Care 2008, 31:569-575.

81. Stevens J, Murray DM, Catellier DJ, Hannan PJ, Lytle LA, Elder JP, Young DR, Simons-Morton DG, Webber LS: Design of the Trial of Activity in Adolescent Girls (TAAG). Contemp Clin Trials 2005, 26:223-233.

82. Webber LS, Catellier DJ, Lytle LA, Murray DM, Pratt CA, Young DR, Elder JP, Lohman TG, Stevens J, Jobe JB, Pate RR: Promoting physical activity in middle school girls: Trial of Activity for Adolescent Girls. Am J Prev Med 2008, 34:173-184.

83. van Sluijs EM, Skidmore PM, Mwanza K, Jones AP, Callaghan AM, Ekelund U, Harrison F, Harvey I, Panter J, Wareham NJ, Cassidy A, Griffin SJ: Physical activity and dietary behaviour in a population-based sample of British 10-year old children: the SPEEDY study (Sport, Physical activity and Eating behaviour: environmental Determinants in Young people). BMC Public Health 2008, 8:388.

84. Trost SG, Pate RR, Freedson PS, Sallis JF, Taylor WC: Using objective physical activity measures with youth: how many days of monitoring are needed? Med Sci Sports Exerc 2000, 32:426-431.

85. Van Cauwenberghe E, Labarque V, Trost SG, De Bourdeaudhuij I, Cardon G: Calibration and Comparison of Accelerometer Cut Points in Preschool Children. Int J Pediatr Obes 2010.

86. Williams HG, Pfeiffer KA, O'Neill JR, Dowda M, Mclver KL, Brown WH, et al: Motor skill performance and physical activity in preschool children. Obesity (Silver Spring) 2008, 16:1421-1426.

\section{Pre-publication history}

The pre-publication history for this paper can be accessed here: http://www.biomedcentral.com/1471-2458/11/485/prepub

doi:10.1186/1471-2458-11-485

Cite this article as: Sherar et al:: International children's accelerometry database (ICAD): Design and methods. BMC Public Health 2011 11:485. 